drinking, with inability to pass a soft tube, or difficulty in its passage at a point near the cardia, with eructations of food without hydrochloric acid and with rennin present, without a tumor in the abdomen but rigidity of the gastric borders, we are not to decide at once that we are dealing with esophageal stenosis, but sometimes with general carcinosis of the stomach.

Naturally, we must restrict this statement to those ages at which cancer is common, but we cannot absolutely exclude such a diagnosis during the earlier period of life, since such instances of carcinoma as early as forty years of age have been observed by me and by others. There is, of course, a possibility of syphilis of the esophagus and stomach, but with the negative Wassermann test such can be readily excluded. As in a long continued dysphagia, existing in one instance under my observation, according to the patient, for twenty years, our conclusion must be at once that it is not malignant, and is due to spasmodic constriction, or to a diverticulum.

REPEHFNCES.

Dr Bertha Erlanger: Beitrllge z.ur Dingnose des Magenkarzinoms mit besonderem Hinweis auf das Schmerzsymptom. Archiv fur Verdauungs-Krankheiten, 10, 728.752

Dr. W. Bauermeister: Zur Semiologie des oesophagoskopischen Bildes. Archiv fur Verdauungs. Krankheiten, 1B, 520.522.

\section{A NOTE ON THE SIMULATION OF DIABETES MELLITUS.}

By Geobge Blumer, M.D., New Haven, Conn.

THe simulation of diabetes mellitus is probably not of very frequent occurrence. The text. books almost ignore the subject; special treatises on diabetes frequently fail to mention it; and even works on the simulation of disease discuss it in a somewhat casual and fragmentary way. The matter is, however, not without interest both from a casuistic and a medico-legal viewpoint. A case recently seen illustrates certain points of interest, particularly the fact that the fraud may not be so obvious at first sight as might be suspected.

The patient, Mrs. X., was an Irish American, 33 years of age, who was sent to me by a physician in a neighboring town for a pruritus of the vulva.

The patient's family history was entirely negative. Her parents and her brothers and sisters were all alive and well, and there was no history of nervous or mental disease in the family.

As a child the patient had had measles, whooping cough, chicken-pox, mumps, tonsillitis, and scarla. tina. There were no complications with any of these diseases. She had had no serious disease as an adult. An ovarian cyst, and incidentally the appendix, was removed six years ago. The menstrual history was normal. The patient married at twentyfour and had one miscarriage at two months, four months before consulting me. There was no vene- real history. The patient had always been a good eater, fond of meat, sweets, and candy. She was not on a special diet at the time she consulted me.

The patient dated the pruritus vulvae from a period twenty months before I saw her. It had appeared rather suddenly, and had been present since that time. It varied in intensity, and tended to be worse at night. It was severe enough at times to interfere with sleep. Urination increased the pruritus. There was no increase in the output of urine. The patient stated that she felt weak, but thought this due to loss of sleep. She had lost twenty pounds in the preceding nine months. There was no general pruritus. The appetite was not abnormal. The patient was very thirsty at times; at other times she "despised" water. She stated that occasionally she had severe frontal headaches with anorexia and even slight nausea. With these her face was flushed. She was more nervous than usual and tended to be constipated.

The physical examination was almost negative. The patient was overnourished and had an excellent color. Her tongue was clean. Her pulse was small and regular and normal in rate. Her blood pressure was 120 systolic and 80 diastolic. The thyroid was normal and there were no glandular enlargements. The lungs were clear. The heart was negative except for a rather short, moderately harsh systolic murmur over the aortic cartilage. The abdomen was negative. The liver and spleen were not enlarged. The kidneys were not palpable. There was no edema of the shins. The pupillary and tendon reflexes were lively. No mammary or ovarian tenderness was present. No sensory changes could be detected.

The patient brought with her a single specimen of urine, stating that her urine had been tested before and that sugar had been reported by at least two physicinns. The specimen presented was light amber in color, hazy, acid in reaction, had a sperific gravity of 1.057 , was free from albumen, and gave a very slight reaction for sugar with Fehling's solution. With Benedict's solution the copper was reduced in an amount that was estimated as representing about $0.25 \%$ of sugar. The polariscope showed $8.5 \%$ of a dextro-rotary substance.

The patient was requested to send a twenty-four hour specimen of urine and was instructed how to collect it. On its arrival the amount was 850 cubic centimeters; it was slightly cloudy, acid in reaction, and had a specific gravity of 1.060 . The urine contained the faintest possible trace of albumen, no acetone, no diacetic acid and no indican. Tests for sugar showed a negative reaction with Benedict's solution and Nylander's solution. The polariscope showed $11.25 \%$ of a dextro-rotary substance. After inversion by heat and acid, copper was reduced and the polariscope showed $3.9 \%$ of a laevo-rotary substance. Rotating substances other than sugars having been excluded, it was clear that the substance originally present in the urine was sucrose, and that inversion had transformed it into dextrose and levulose, the latter preponderating and causing the lnevo rotation. Professor Lafayette Mendel was kind cnough to examine the specimen and to confirm the diagnosis of sucrosuria.

The patient's physician was communicated with and informed of the findings. On account of the local symptoms he was able to suggest a bladder examination and to obtain a catheterized specimen of urine. This specimen when examined in the lab- 
oratory here was absolutely free from sugar of any kind, as were subsequent specimens obtained by catheterziation and examined by the patient's family physician.

It was evident then that the patient was not suffering from diabetes mellitus, but that she had purposely added sucrose to the urine in order to simulate this disease. The psychology underlying this deliberate deceit was not perfectly clear. The patient was not hysterical in the strict sense of the term and did not show the physical manifestations of hysteria. She was distinctly neurotic, and according to her family physician had been known on one previous occasion to feign illness in order to compass certain aims in connection with her family life. This was probably the explanation of the simulated diabetes, though the family physician could not discover what particular object the patient had in view.

The simulation of diabetes probably dates back to an early period in the popular knowledge of the disease. Heller cites cases in 1858 (Oester. Zeit. f. Pralkt. Heilkunde, 1858, vol. iv, pp. 419 and 481) and states that the laity were acquainted with the disease at that time. It is probable that in German-speaking countries widespread popular knowledge of the urinary changes was developed earlier than in other countries on account of the popular name "zuckerkrankheit."

The simulation of the disease may take three forms: (1) the addition to the urine of sucrose; (2) the addition to the urine of glucose; and (3) the production of an artificial glycosuria by the consumption of phloridzin or phloroglucin. The last named form of simulation is suggested by Stier as a possibility though he cites no actual cases (Stier in Becker, Die Simulation von Krankheiten, Leipzig, Thieme, 1908).

Simulation of diabetes mellitus is easier than that of many other diseases because of the lack of objective physical phenomena in mild and uncomplicated cases, and because the urine in such cases presents no characteristic chemical abnormalities aside from the presence of sugar. The detection of sucrosuria is simple if certain precautions in the care of the urine are observed. Failure to observe these is what has led to failure to detect the imposture. If the urine is allowed to stand after collection, especially if in a warm place, inversion of the sucrose into dextrose and levulose may occur either as the result of bacterial action or even apart from this. In such a case reduction of copper will occur and will throw the physician off his guard, unless he happens to note the great disparity between the degree of copper reduction and the specific gravity of the urine. In the extraordinary case of Abeles and Hoffman (Wiener Med. Presse, 1876, vol. xvii, pp. 1507 and 1537) and in our case such inversion did take place, and in both instances misled some of the physicians who tested the urine.

Where the patient is unusually intelligent and well informed, glicose is added to the urine and detection of the fraud becomes difficult especially if there is nothing to arouse the sus. picion of the physician. A patient who is intelligent enough to add glucose to the urine has usually read up the subject in an encyclopedia or text-book and may not only give a typical history, but may even add water to the urine with the sugar in order to simulate the polyuria and do away with the disparity between sugar content and color and quantity of urine which might put the observer on his guard. Stier cites one case where a well educated man under accusation for certain moral delinquencies actually did this. In Abeles and Hoffman's Karlsbad pa. tient sucrose was first added to the urine, but the patient returned to them the following year with glycosuria and actually introduced the glucose into her bladder so that catheterized specimens obtained at periods named by her showed a saccharine urine. Most simulators are not so intelligent as this and are apt to make the mistake of adding too much glucose so that such an unusual urinary picture is produced that suspicion is aroused.

The detection of the simulation depends in the first place on the occurrence of some factor which arouses suspicion in the mind of the physician. In soldiers or in cases with a medicolegal bearing this suspicion is much more likely to be aroused than it is in cases occurring in ordinary civil practice. The detection of sucro. suria is, as stated, simple if the urine is exam. ined fresh. In this case there is no inversion of the sucrose and no copper reduction, and we have a high specific gravity urine with large amounts of dextro-rotary sugar shown by tho polariscope, which on artificial inversion splits to dextrose and levulose. Even where some spontaneous inversion has occurred the tremendous disproportion between the copper reduction and the specific gravity should at once cause suspicion; also the fact that there is no increase in the amount of urine and that the color is high. The simulation is, of course, confirmed by the examination of urine passed by the male patient in the presence of the examiner or obtained by catheterization from female patients-preferably after washing out the bladder with saline solution.

The detection of simulated glycosuria is more difficult if the patient is intelligent enough not to put in too much glucose. Formerly, commercial glucose was not chemically pure and contained sugar intermediate between dextrin and dextrose. This sugar showed much higher polariscope readings than it did copper reduction and could be detected by this means, as Abeles and Hoffmann showed in their case. This is still the case with some commercial glucose, but would not be the case if the patient used a chemically pure product. When suspicion is aroused, however, catheterized specimens will clear up the case; though, in view of the experience of Abeles and Hoffman, even these must be 
obtained when the patient does not suspect their purport.

If there is suspicion that an artificial diabetes is being produced by the consumption of phloridzin or phloroglucin the isolation of the patient away from possible supplies of the drugs in question would seem to be the only rational procedure.

\section{NOTES OF $\Lambda$ CONFERENCE ON THE MEDICAL ANI SOCIAL ASPECTS OF SYPHILIS OF THE NERVOUS SYSTEM.}

Held at the Psychopathic Hospital, MАY 27, 1915.

(Scrics continucd from page 15).

IX.

'The Development of the Gold Sol "Paretic" Reaction as Compared with the "CerebroSPINAL SyPhilitic" TyPe, CONSIDERED From the Time Necessary to Form a Completed REACTION.*

I3Y H. C. Solomon, M.D., Boston,

\section{$\triangle N D$}

İ. S. Welles, Boston.

THE "cerebrospinal syphilitic" type reaction, as most characteristic, is strongest in the third, fourth and fifth tubes, grading off in the first and second tubes and those of the high dilution. Less characteristic is a curve reaching its height in the first tube, but not going as high as 5 plus reaction.

If one charts the gold sol curves at short intervals in the development of the "paretic curve," one finds that there are curves having the form of the second type mentioned of cerebrospinal syphilis reactions, i.e. at the end of three or more hours it may have progressed no farther than a 3 plus, while at the end of 12 hours it will have reached a 5 plus reaction. But, in quite a considerable number of cases, one finds that the reaction begins most strongly in the third, fourth, and fifth tubes, and is weak$\mathrm{er}$ in the first and second and the higher diluted tubes. so that read at an earlv time. the curve will be identical with that of the so-called typical "cerebrospinal syphilitic" type, i.e., it has gone through the same reaction, but has finally gone farther, whereas the "cerebrospinal syphilitic" type, that started the same, has halted in its development, or, as one might possibly express it, is a forme fruste of the "paretic" reaction.

- Being S. B. I. Contribution whole number $180 \quad$ (1015.88). (Bibliographical Note.-The previous contribution was by E. E. the Question of General Paresis- entitled "Latent Neurosyphllis and Sivarical, Jounnal, Vol.. clxxiv, No. 1, page 8.
The following charts of the development of the "paretic curve" by three fluids from paretics are illustrative examples.

\section{Chart I}

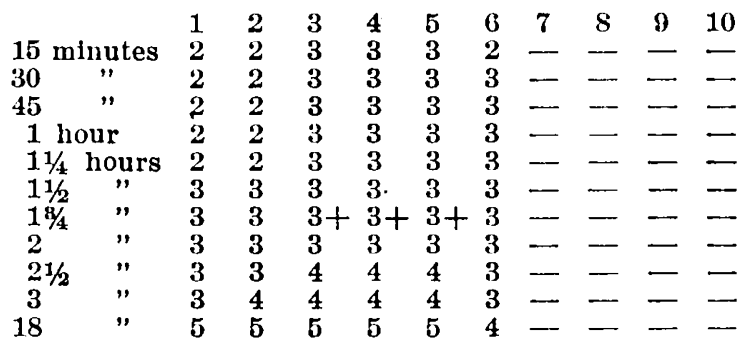

\section{Chart II.}

15 minutes
30 "
45 hour
1 hours
$11 / 4$ "
$11 / 2$
$1 \% / 4$
2
$21 / 2 \quad "$
3
18

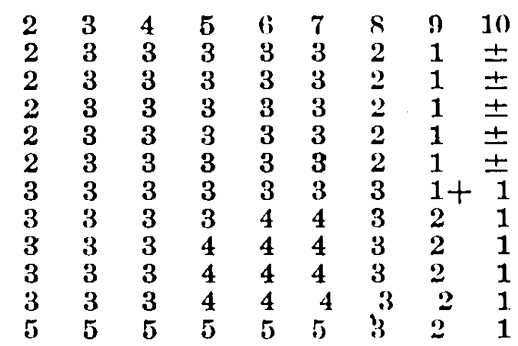

Chart III.

\begin{tabular}{|c|c|c|c|c|c|c|c|c|c|c|c|}
\hline & 1 & 2 & 3 & 4 & 5 & (j) & 7 & 8 & 0 & 10 \\
\hline & & 2 & 3 & 3 & 3 & 3 & 3 & 1 & 1 & - & - \\
\hline 30 & $"$ & 3 & 3 & 3 & 3 & 3 & 3 & + & + & - & - \\
\hline 45 & $"$ & 3 & 3 & 3 & 3 & 3 & 3 & + & + & 一 & 一 \\
\hline 1. $\mathrm{h}$ & ur & 3 & 3 & 3 & 3 & 3 & 3 & + & + & - & - \\
\hline $11 / 4$ & hours & 3 & 3 & 3 & 3 & 3 & 3 & $1-$ & & - & - \\
\hline $11 / 2$ & $"$ & 3 & & 3 & 0 & 3 & 3 & 2 & 2 & \pm & - \\
\hline $13 / 4$ & $"$ & 3 & 3 & 3 & 4 & 4 & 4 & 2 & 2 & 1 & \\
\hline 2 & $"$ & 3 & 3 & 3 & 4 & 4 & 4 & 2 & , 2 & 1 & \\
\hline $21 / 2$ & $"$ & 3 & 3 & 3 & 4 & 4 & 4 & 2 & 2 & 1 & - \\
\hline 3 & $"$ & 3 & & 3 & 4 & 4 & 4 & 2 & 2 & 1 & \\
\hline 18 & $"$ & 5 & & 5 & 5 & 5 & 5 & 2 & 2 & 1 & \\
\hline
\end{tabular}

\section{$\mathbf{x}$}

Syphilis and the Psychopathic Hospital: Notes on Medical and Social Progress, Especially in Neurosyphilis, Boston, MasSACHUSETTS, 1915.*

By I. I. Southakd, M.D., Boston,

Divector of the Psychopathic Hospital, Boston; Pathologist, Massachusetts State Board of Insanity, and Bullard Professor of Neuropathology, Harvard Medical School.

\section{Anstract}

I. Comparative Importance of Syphilis in Psychopathic Work.

II. Some Recent Local Laboratory Statistics (W. A. Hinton, Harvard Neuropathological Testing Laboratory).

III. Economic Notes.

IV. Adler's Point in Salvarsan Therapy.

Being 8. B. I. Contribution whole number 181 (1916.81) Bibliographical Note.-The previous contribution was by $\mathbf{H}_{6}$. C. Solomon and E. S. Welles, entitled "The Development of the Gold Sol 'Paretic' Reaction As Compared with the 'Cerebrospinal Byphl litic' Type, Considered from the Time Necessary to Form a Com pleted Reaction," BosroN
Vol. clxxiv, No. 2, page 60. 